\title{
AGENESIS OF THE CORPUS CALLOSUM
}

\author{
J. N. Harcourt-Webster, M.A., M.B., B.Chir.* \\ J. H. RACK, M.A., M.B., B.Chir. \\ Junior Assistant Pathologist \\ Assistant Pathologist
}

Department of Pathology, University of Cambridge

COMPLETE or partial agenesis of the corpus callosum is uncommon especially in adults; the incidence amongst patients in institutions where numerous air encephalograms are performed is 3\% (Carpenter and Drukemiller, 1953). Reil (1812) published the first report of a case, describing the necropsy findings in a 30 year old woman of low mentality; further cases discovered at necropsy were subsequently reported (Urquardth, 1880; Richter, 1886; Bruce, 1889; Dunn, 1889; Cameron, 1917; de Large, 1925). Baker and Graves (1933) reviewed 83 cases, in a wide variety of age groups, first diagnosed at necropsy. The diagnosis during life was first made by Davidoff and Dyke (1934) using pneumo-encephalography; the pneumo-encephalographic features had been observed by Guttman (1929) but their significance was not appreciated until necropsy revealed complete agenesis. Fukai, Oguma and Sujiyama (1960) reviewed 187 cases of complete and partial agenesis; 130 cases were proven at necropsy, 57 diagnosed by pneumo-ence phalography only. Since their review a further 22 cases have been reported, 7 diagnosed or confirmed at necropsy, 15 diagnosed by pneumo-encephalography only.

The function of the corpus callosum, originally regarded as the seat of the soul (Mingazzini, 1922), has been much discussed both on the evidence from cases of complete and partial agenesis and from that following surgical division in man and experimental animals. No characteristic clinical syndrome accompanies complete or partial agenesis of the corpus callosum nor are there any specific neurological or psychiatric accompaniments. In some cases of congenital agenesis there are no readily detected deficiencies; the 25th such case, which is also the 17th asymptomatic adult with complete agenesis, is here reported with a short review of the literature.

*Present Address: Department of Pathology, University of Edinburgh.

\section{Case Report}

A 65-year-old builder's labourer was admitted to hospital with a three months history of flatulence and epigastric discomfort. He claimed to have been fit and well all his life, a statement corroborated by his relatives and medical records. Shortly before the onset of his symptoms, he had attended the Opthalmic Department with some loss of vision; this was found to be due to cataracts and he was awaiting their surgical removal at the time of admission. There was no relevant family history and no noteworthy abnormality of his central nervous system or mental state.

A radiological diagnosis of carcinoma of the stomach was made and substantiated at laparotomy. Sub-total gastrectomy was performed and the diagnosis confirmed histologically, but bronchopneumonia supervened and he died on the fourth postoperative day.

\section{Necropsy}

There was no unusual feature at the site of the Polya gastrectomy; there was no residual tumour or metastasis. The lungs showed the changes of bronchopneumonia, confirmed histologically.

Brain $(1173 \mathrm{~g}):$. On removing the dura mater a large volume of cerebro-spinal fluid escaped from a common ventricle. There was no falx cerebri or tentorium cerebelli. The hemispheres were symmetrical and united along their supero-medial borders by a tough membrane (Fig. 1). The corpus callosum and septum lucidum were absent, there being a widely patent common ventricle (Fig. 2). On the inferior aspect, because of the absence of the anterior columns of the fornix and the anterior commissure, there was a free communication with the common ventricle (Fig. 3). There was no abnormality of the Circle of Willis or cerebral arteries. The lateral surface of the hemispheres showed a normal sulcal and gyral pattern, whilst an anterior view similarly presented a normal contour.

After fixation in $15 \%$ formol saline and radiographic examination (Fig. 4), the mid-brain was divided transversely and the cerebrum mid-sagitally. The pieces were weighed and compared with another similarly divided brain from a man of similar age and stature (Fig. 5). The lateral ventricles were large with symmetrical dilatation of the anterior and posterior horns; the inferior horns were absent. Whilst fragments of the choroid plexus were attached to the medial surfaces of the hemispheres, no fragments were attached to the walls of the lateral ventricles or their horns. An unusual reflection of the meninges joined the two cerebral hemispheres together, whilst another shorter reflection connected the occipital lobes with the cerebellum (Fig. 6). 


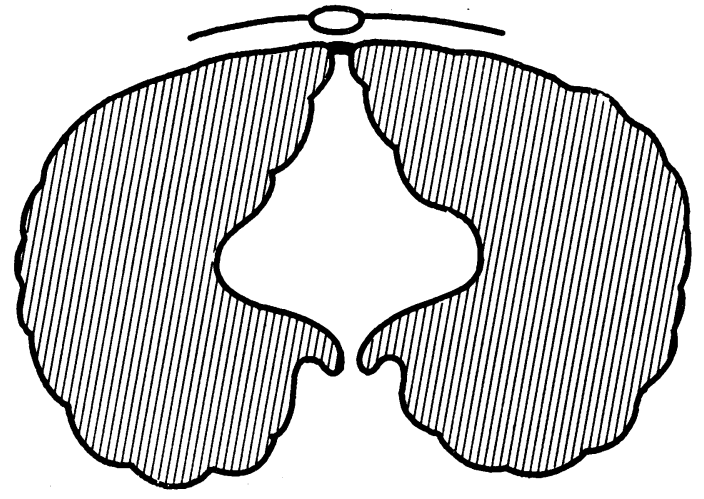

Cross section of this case.

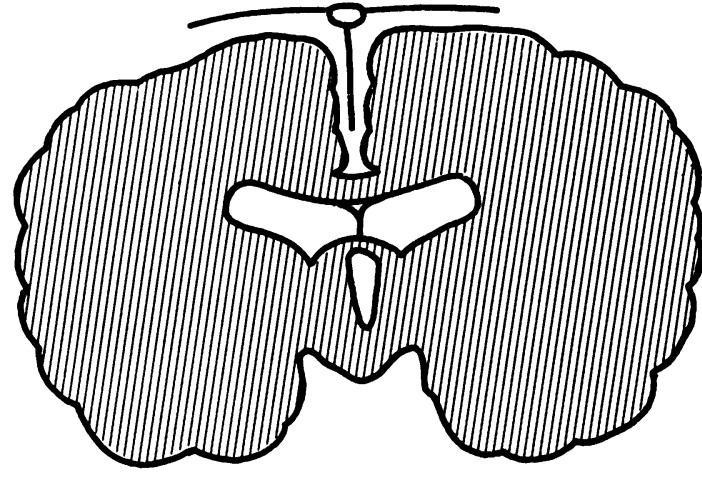

Cross section of normal brain.

FIG. 1.-Diagrammatic comparison of this case with the normal. The corpus callosum and septum lucidum are absent, the two hemispheres being joined along their superomedial borders by a membrane.

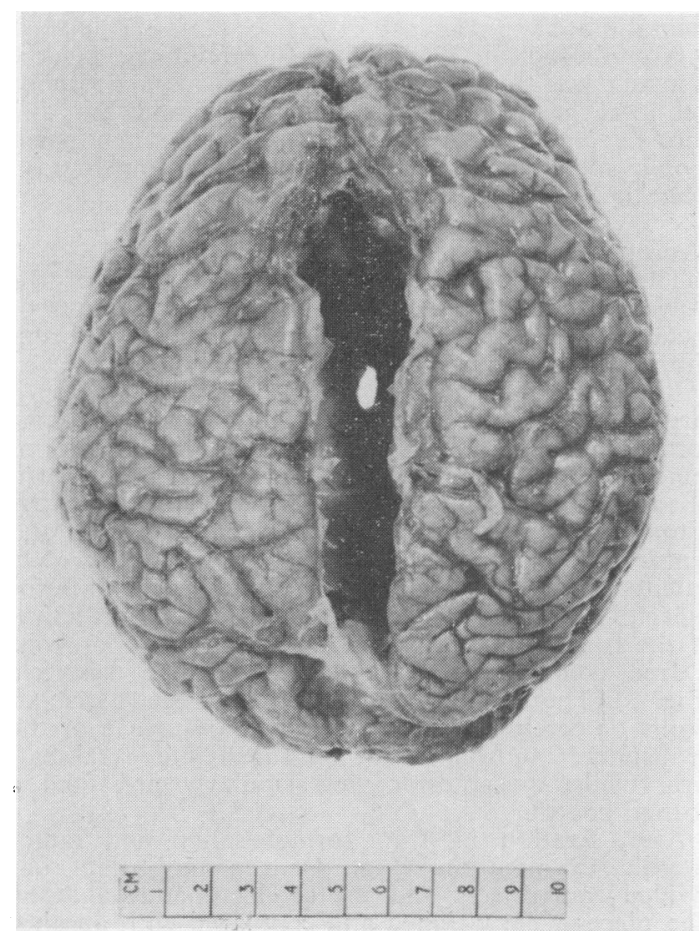

Fig. 2.-View from above through the widely patent common ventricle.

The cerebral hemispheres were cut into coronal slices $1 \mathrm{~cm}$. thick; this revealed a considerable deficiency in the grey and white matter. The anterior commissure, forceps minor, septum lucidum, pineal body, stria habenularis and the genu, body and splenium of the corpus callosum were not found. With the exception of slightly raised areas at the site

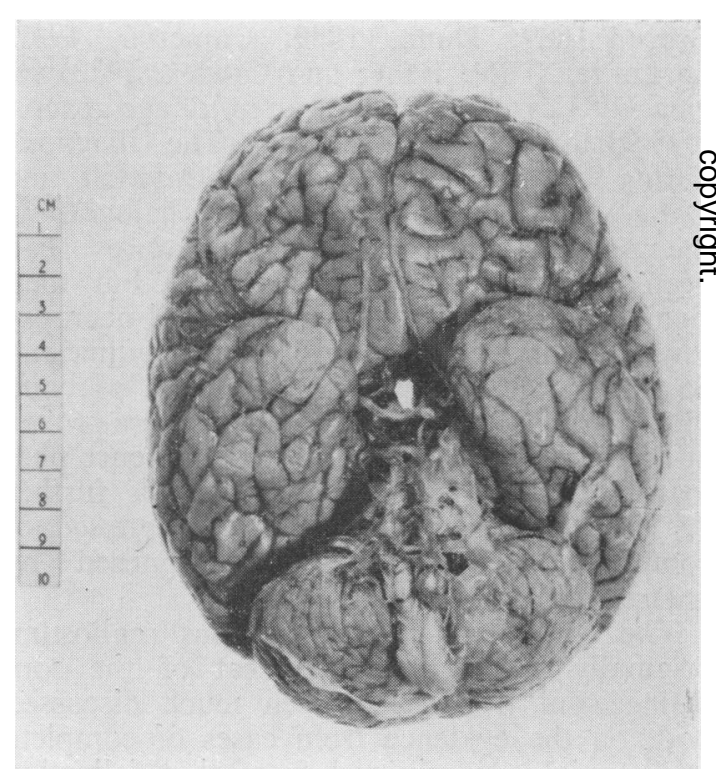

Fig. 3.-View from below. This shows the free communication with the common ventricle due to the absence of the anterior columns of the fornix and the anterior commissure.

of their attachments both the anterior and posterior columns and the body of the fornix were also absent. The basal ganglia and the attachments of the cranial on nerves, including the optic commisure and tracts, were normal.

There was no abnormality on sectioning the midbrain, pons, medulla oblongata and cerebellum. 


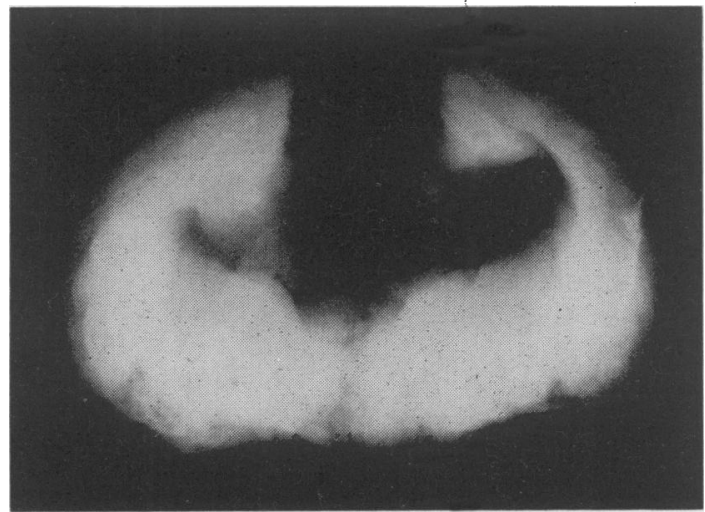

FIG. 4.-Radiograph demonstrating the wide common ventricle and its large lateral extensions.

THIS CASE

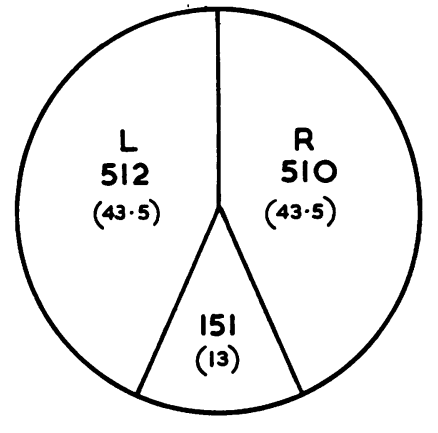

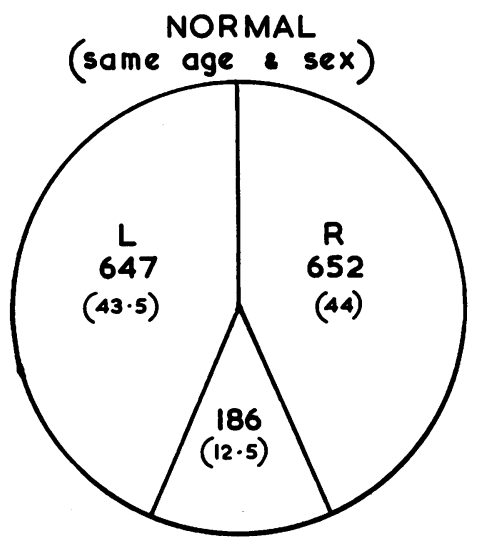

Weight in grams. Figures in brackets are percentages of total weight.

FIG. 5.-Diagrams to show the relative sizes of the left hemisphere, right hemisphere and cerebellum (including brain stem).
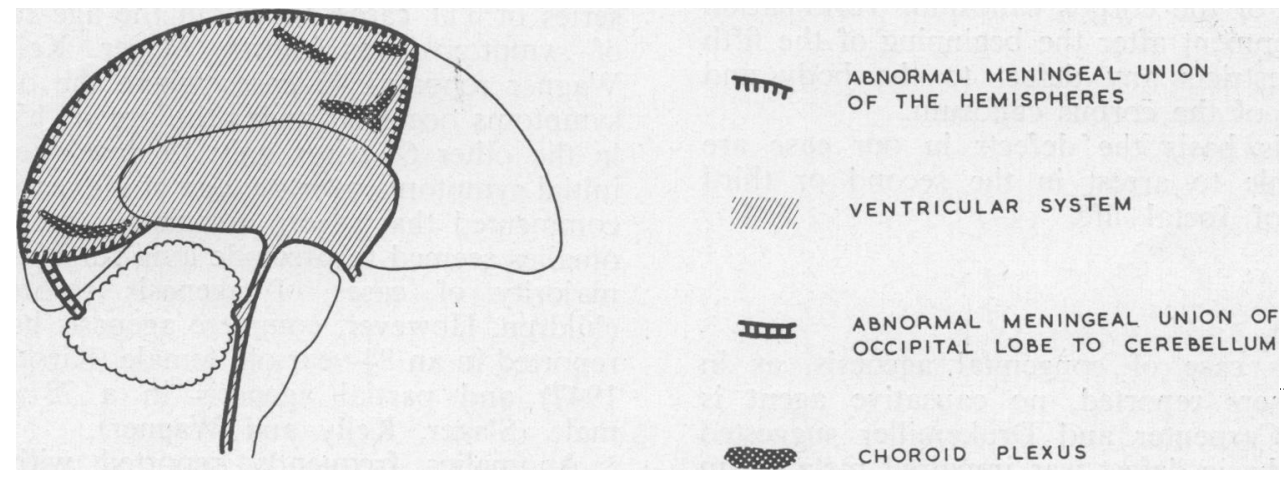

Fig. 6.-Diagram of the medial surface to show the reflection of the meninges joining the two cerebral hemispheres and that between the occipital lobes and the cerebellar hemispheres. 


\section{Embryology}

The corpus callosum develops from the lamina terminalis where a thickening develops during the third or fourth month of foetal life. This thickening is on the dorsal and cephalic aspects of the hippocampal commissure which has just formed; the inferior part of the thickening becomes the anterior commissure while the remainder forms the corpus callosum (Davidoff and Epstein, 1950).

Growth of the corpus callosum first occurs in a cephalic direction, then dorsally, to form the rostrum and genu. In the final stage growth is in a caudal direction, the corpus carrying the hippocampal commissure on its undersurface. The septum lucidum represents pieces of each cerebral hemisphere which are separated from the remainder of the hemispheres by the growth of the corpus callosum and the formation of the fornix. Development is complete by the end of the fifth month (van Epps, 1953; Sheldon and Pegman, 1953).

The anatomical defects seen in the various types of agenesis are determined by the stage at which normal development is interrupted (Bruce, 1889). Arrest within the first three weeks of foetal life results in complete fusion of the hemispheres and ventricles with no distinct commissures between the hemispheres (Mosberg and Voris, 1954; Marburg, 1949; Slager, Kelly and Wagner, 1957). If arrest occurs at any stage between the end of the first and the beginning of the fourth month, there is complete agenesis of the corpus callosum, septum lucidum, anterior commissure and hippocampal commissure (Jackson, Sinclair and Belber, 1960). Should development terminate late in the fourth month the anterior commissure, rostrum and genu will be present but not the body or splenium of the corpus callosum. Termination of development after the beginning of the fifth month restricts any defect to the body and splenium of the corpus callosum.

On this basis the defects in our case are attributable to arrest in the second or third months of foetal life.

\section{Aetiology}

In this case of congenital agenesis, as in most others reported, no causative agent is known. Carpenter and Drukemiller suggested that the basic defect was impaired metabolism due to anoxia; Sander (1868) considered maldevelopment of the anterior callosal artery with inadequate vascularisation of the neuropore to be a cause. However, to attribute age- nesis to a defect in the embryonic blood supply or in the development of the lamina terminalis is merely to suggest the mechanism without $c$ determining the fundamental aetiology. Various agents have been suggested.

1. Genetic defect: Naiman and Clark Frazer (1955) reported two cases of complete agenesis in siblings.

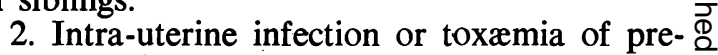
gnancy (Wilson, 1954).

3. Transient barriers in embryonic life such $\stackrel{\infty}{\oplus}$ as a cyst within the ventricular system (de? Morsier and Mozer, 1935; Oftedal, 1959).

\section{Discussion}

Complete or partial agenesis of the corpus callosum is diagnosed most commonly in the youngest age groups with no significant differ- $A$ ence in incidence between the sexes (Bunts ? and Chaffee, 1944; Carpenter, 1954). Bunts $\omega$

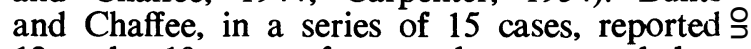
12 under 10 years of age and commented that $\overrightarrow{7}$ the majority of cases developed symptoms be- $\frac{T}{D}$ fore this age. Carpenter and Drukemiller re- $\frac{0}{2}$ viewed 45 cases with a similar finding; in $25 \frac{\mathrm{g}}{2}$ the onset of symptoms occurred under two years of age, in eight under 10 years of a $\vec{E}$. and in only two cases reported by them dit the onset of symptoms occur after 20 years age. Hankinson and Amadore (1957) reviewed ? a further 14 cases and divided them into two groups. There were 11 infants some of whom presented with failure to thrive or with periodic $\frac{\varnothing}{2}$ vomiting and irritability so that a subdural $\overrightarrow{\vec{A}}$ hæmatoma or other intra-cranial lesion was considered; the others presented with rapidly or gradually rising intra-cranial pressure. The re-o maining three cases all presented as epileptics of late onset, the oldest being 46 years. In a 3 series of 111 cases, in whom the age of onset:of symptoms was known, Slager, Kelly and 3 . Wagner reported 45 cases where the onset of $\delta$ symptoms occurred under the age of 15 years; in the other 66 cases only 19 developed theiro initial symptoms over the age of 40 years. They commented that severe associated cerebral an-o omalies seemed to preclude long survival in the majority of cases of agenesis recorded ino children. However, complete agenesis has been 0 reported in an 84-year-old female (Kirschbaum, 1947) and partial agenesis in a 73-year-old male (Slager, Kelly and Wagner).

Anomalies frequently reported with com- $\frac{0}{0}$ plete or partial agenesis of the corpus callosum $\stackrel{\oplus}{-}$ include dilatation of the posterior horns of the 0 lateral ventricles with thinning of their wallso as in our case, non-union of the calcarine and $\stackrel{\circ}{\Phi}$ 
parieto-occipital sulci by interposition of a superficial gyrus, and radial arrangement of the sulci on the medial surface of the brain as seen in the foetus. Total absence of the septum lucidum and hippocampal commissure is found with complete agenesis though, unlike our case, the body and columns of the fornix are usually present (Baker and Graves, 1933). Other anomalies often reported include cranial nerve defects, incomplete separation of the frontal lobes, hydrocephalus, porencephaly, arrhinencephaly, microcephaly and dilatation of the cisterna magna (Bouchier, 1957). In some cases the anterior commissure is larger than normal (Norman, 1958).

Baker and Graves observed that the mentality of patients with agenesis varied considerably but was fairly well correlated with the severity of the associated anomalies. They suggested that the various symptoms reported in many cases of complete or partial agenesis were a manifestation of the accompanying anomalies rather than of the defect in the corpus callosum. This is supported by cases where the defect follows hæmorrhage, neoplasm or surgery; the symptoms probably result from damage to adjacent areas (Kirschbaum, 1947; Greenblatt and Anderson, 1953).

Considerable controversy has occurred regarding the function of the corpus callosum and it is of interest that of 209 reports of complete and partial agenesis 24 were asymptomatic during life. The only significant common feature of these latter cases, which vary in age from 11 months to 76 years, is the accidental discovery of complete or partial agenesis at necropsy.

A definite function for the corpus callosum was suggested by the loss of memory of topography, with visual and tactile agnosia, after the surgical division of the posterior half of the corpus callosum during the removal of a colloid cyst from the third ventricle (Trescher and Ford, 1937). Further evidence of a function was the apraxia attributed to involvement of the callosal fibres by an aneurysm abutting on the corpus callosum (Sweet, 1941).

Evidence against a definite function for the corpus callosum was, for many years, considerable. Cameron (1917) and Dandy (1936) found no abnormality in patients in whom the corpus callosum was surgically divided. Van Wagenen and Yorke Herren (1940) divided the corpus callosum of 10 epileptic patients to prevent generalisation of the fits and found that section of the commissural pathways contained in the corpus callosum could be performed without any untoward effect. Intensive studies were made on these patients and six others, the pre-operative and post-operative findings being carefully compared (Akelaitis, 1941; Smith and Akelaitis, 1942); no evidence of any significant abnormality was found. Other workers found that complete or partial division of the corpus callosum caused dyspraxia in the subordinate or dominant hand only when there was also damage to the subordinate or dominant hemisphere (Akelaitis, Riksteen, Yorke Herren and Van Wagenen, 1942). These authors and later Myers (1956), concluded that the bilateral functions such as motor activity are integrated through commissural pathways at levels below the corpus callosum.

During the past ten years numerous investigations of the processes of inter-hemispheric transfer of learning have demonstrated definite functions for the corpus callosum. Myers (1956; 1961) studied the role of this structure in the transfer of visual learning in cats whose optic chiasma and corpus callosum had previously been divided. Cats trained with one eye masked were unable to remember with the second eye what they had learned with the first eye. Furthermore the second eye could be used to learn the complete reverse of what the cat had been trained to do with the first; this indicated a complete functional independence of the separated hemispheres, a conclusion supported by Sperry, Stamm and Miner (1956). Sperry (1958), studying somesthetic and motor learning in similarly treated monkeys, found that in this species the independence of the separated hemispheres was less clear cut, there sometimes being transfer of learning from one hand to the other. Further investigation into the occurrence of such transfer showed that the corpus callosum when present did play an important transfer role between the hemispheres (Glickstein and Sperry, 1960). Nevertheless it is well established that either forelimb can be controlled from a single hemisphere in a splitbrain cat or monkey. Myers (1962), using splitbrain animals taught various tasks by presenting one task to one eye and another to the other eye, demonstrated that by careful selection of the tasks used, the absence of interaction, facilitation of learning or interference between the hemispheres could be demonstrated.

The function of the corpus callosum is believed to be that of supplementing the activity of each cerebral hemisphere with both complementary and contrary information about what is occurring in the other hemisphere rather than effecting a bilateral spread of information; 
in persons with complete absence of the corpus callosum the organisation of the brain is undoubtedly very different from the normal but much work needs to be done in developing experimental psychological tests on the lines suggested by animal experiments before defects in inter-hemispheric transfer can be detected.

\section{Summary}

Agenesis of the corpus callosum is an uncommon abnormality; excluding the case reported, there are some 209 examples of complete or partial agenesis in the literature. All age groups are represented but many cases are diagnosed in infancy or childhood because of severe symptoms or early death, both attributed to associated anomalies of the brain and not to the defect in the corpus callosum. There is, however, a group of 25 asymptomatic cases of complete or partial agenesis; of these 17, including the present case, are adults with complete agenesis. The aetiology of most cases is unknown. The function of the corpus callosum is believed to be that of supplementing the activity of each hemisphere with information from the other hemisphere rather than bringing about a bilateral spread of information; tests for the detection of abnormalities in inter-hemispheric transfer have yet to be evolved.

We wish to thank Mr. B. McN. Truscott for permission to publish this case, the Department of Medical Photography, The United Cambridge Hospitals for the illustrations, and Professors R. T. N. Greaves and G. L. Montgomery for their criticism and advice.

\section{REFERENCES}

Akelaitis, A. J. (1941): Studies on Corpus Callosum. Higher Visual Functions in each Homonymous Field following Complete Section of Corpus Callosum, Arch. Neurol. Psychiat., (Chicago), 45, 788.

- Riksteen, W. A., Yorke Herren, R. and VAN WAGENEN, W. P. (1942): Studies on Corpus Callosum. Contribution to the Study of Dyspraxia and Apraxia following Partial and Complete Section of Corpus Callosum, ibid., 47, 971.

Baker, R. C. and Graves, G. O. (1933): Partial Agenesis of the Corpus Callosum, ibid., 29, 1054.

BouCHIER, I. A. D. (1957): Agenesis of the Corpus Callosum, S. Afr. med. J., 31, 1220.

BRUCE, A. (1889): On the Absence of the Corpus Callosum in the Human Brain, Rep. Lab. $R$. Coll. Physicians Edinb., 1, 70.

Bunts, A. T. and Chaffee, J. S. (1944): Agenesis of the Corpus Callosum with Possible Porencephaly; Review of the Literature and Report of a Case, Arch. Neurol. Psychiat., (Chicago), 51, 35.

Cameron, J. L. (1917): The Corpus Callosum: A Morphological and Clinical Study, Canad. med. Ass. J., 7, 609 .
Carpenter, M. B. (1954): Agenesis of Corpus Callosum: Study of 18 Cases Diagnosed during Life, Neurology, 4, 200.

, and DruKemiller, W. H. (1953): Agenesis of the Corpus Callosum Diagnosed during Life, Arch. Neurol. Psychiat., (Chicago)., 69, 305.

DANDY, W. E. (1936): Operative Experience in Cases of Pineal Tumours, Arch. Surg., 33, 19.

DAVIDOFF, L. M. and DYKE, G. A. (1934): Agenesis of the Corpus Callosum: Diagnosis by Encephalography; Report of three cases, Amer. J. Roentgenol., 32, 1.

, and EPSTEIN, B. (1950): In 'The Abnormal Pneumoencephalogram', 1st. ed. p. 429. Philadelphia: Lea and Febiger.

DunN, L. A. (1889): Case of Complete Primary Absence of Corpus Callosum, Guy's Hosp. Rep., 46, 117.

VAN EPPS, E. F. (1953): Agenesis of the Corpus Callosum with Congenital Malformation including Atresias of Foramens of Luschka and Magendie, Amer. J. Roentgenol., 70, 47.

FukaI, H., OGUMA, Y. and SujIYAMa, Y. (1960): Agenesis of the Corpus Callosum: Report of Three Cases and Review of the Literature, Brain Nerve, 12, 772.

Glickstein, M. and SPERRY, R. W. (1960): Intermanual Transfer in Split-Brain Monkeys after Somatic Cortical Ablation, Amer. Psychologist, $15,485$.

Greenblatt, J. and ANDERSON, C. (1953): Partial Agenesis of Corpus Callosum with Porencephaly, Conn. State med. J., 17, 824.

GUTTMAN, L. (1929): Uber einen Falle von Entwicklungastörung des Gross-und Kleinhirns mit Balkenmangel, Psychiat. neurol. Wschr., 31, 453.

Hankinson, J. and Amadore, L. V. (1957): Agenesis of the Corpus Callosum Diagnosed by Pneumo-encephalography, Brit. J. Radiol., 30, 200.

JaCKSON, F. E., Sinclair, J. and Belber, C. J. (1960): Agenesis of the Corpus Callosum: Its Pneumo-encephalographic and Angiographic Appearance, Brit. med. J., ii, 42.

Kirschbaum, W. R. (1947): Agenesis of the Corpus Callosum and Associated Malformations, J. Neuropath., 6, 78.

DE LARGE, G. (1925): On Brains with Total and Partial Lack of Corpus Callosum and on Nature of Longitudinal Callosal Bundle, J. nerv. ment. Dis., 62, 449.

MarburG, O. (1949): So-called Agenesia of the Corpus Callosum (Callosal Defect) Anterior Cerebral Dysraphism, Arch. Neurol. Psychiat., (Chicago), 61, 297.

MingazzinI, G. (1922): Der Balken: Eine anatomische, Physiopathogische and kilinische Studie, p. 212. Berlin: Springer.

DE Morsier, G. and Mozer, J. J. (1935): Agénésie Complète de la Commissure Calleuse et Troubles du Dévelopment de l'Hémisphère Gauche avec Hémiparésie Droite et Intégrité Mentale, Schweiz Arch. Neurol. Psychiat., 35, 317.

Mosberg, W. H. JR. and Voris, H. C. (1954): Unusual Congenital Anomaly of Brain: Agenesis of Corpus Callosum, Absence of Septum Pellucidum and Fusion of Cerebral Hemisphere, $J$. Neuropath., 13, 369.

MYERS, R. E. (1956): Function of Corpus Callosum in Interocular Transfer, Brain, 79, 358. 
(1961): Corpus Callosum and Visual Gnosis. In Brain, Mechanisms and Learning, ed. A. Fessard. Oxford: Blackwell. , (1962): Transmission of Visual Information Within and Between the Hemispheres: A Behavioural Study. In Interhemispheric Relations and Cerebral Dominance, ed. V. B. Mountcastle, p. 51. Baltimore: Johns Hopkins.

Naiman, J. and Clark Frazer, F. (1955): Agenesis of Corpus Callosum: Report of Two Cases in Siblings, Arch. Neurol. Psychiat., (Chicago), 74, 182.

NoRMaN, R. M. (1958): In Neuropathology, ed. Greenfield, p. 320. London: Arnold.

OFTEDAL, S. I. (1959): Anomalies of the Mid-Line Structures of the Brain. Agenesis Corporis Callosi with a Mid-Line Cyst in One Case and a Lipoma (?) in Another, Acta psychiat. scand., 34, 451.

REIL, J. C. (1812): Mangel des mittleren und freien Theils des Balkans in Menschengehion, Arch. Physiol., 11, 341.

RICHTER, A. (1886): Ueber die Windungen des Menschlichen Gehirns, Virchows Arch., 106, 380.

SANDER, J. (1886): Ueber Balkenmangel in Menschlichen Gehirn, Arch. Psychiat., 1, 229.

Sheldon, P. and Pegman, A. (1953): Radiological Appearances of Agenesis of Corpus Callosum, J. Neurol., 16, 117.

Slager, V. T., Kelly, A. B. and Wagner, J. A. (1957): Congenital Ábsence of the Corpus Callosum: Report of a Case and Review of the Literature, New Engl. J. Med., 256, 1171.
Smith, K. U. and Akelaitis, A. J. (1942): Studies on Corpus Callosum. Laterality in Behaviour and Bilateral Motor Organisation in Man Before and After Section of the Corpus Callosum, Arch. Neurol. Psychiat., (Chicago), 47, 519.

Sperry, R. W., Stamm, J. S. and Miner, Nancy (1956): Relearning Tests for Interocular Transfer Following Division of Optic Chiasma and Corpus Callosum in Cats, J. Comp. Physiol. Psychol., 49, 529.

(1958): Corpus Callosum and Interhemispheric Transfer in the Monkey, Anat. Rec., 131, 297.

SWEET, W. H. (1941): Sleeping Intracranial Aneurysm Simulating Neoplasm: Syndrome of Corpus Callosum, Arch. Neurol. Psychiat., (Chicago), 45, 86.

Trescher, J. H. and Ford, F. R. (1937): Colloid Cyst of the Third Ventricle: Report of a Case; Operative Removal with Section of the Posterior Half of Corpus Callosum, ibid, 37, 959.

URQuHARDTH, A. R. (1880): Case of Congenital Absence of the Corpus Callosum, Brain, 3, 408.

Van Wagenen, W. $P$. and Yorke Herren, $R$. (1940): Surgical Division of Commissural Pathways in the Corpus Callosum: Relation to Spread of an Epileptic Attack, Arch. Neurol. Psychiat., (Chicago), 44, 740.

Wilson, S. A. K. (1954): In Textbook of Neurology, 2nd. ed. vol. 11, p. 1255. London: Butterworth. 